\title{
Surgery of the Goiter in the ENT Department of Chu Gabriel Toure: Problematic and Perspective
}

\author{
Kassim Diarra1, N'faly Konaté1, Youssouf Sidibé2, Tiguida Sissoko¹, Fatogoma Issa Koné1, \\ Boubacary Guindo1, Harouna Sanogo ${ }^{3}$, Bagayoko Drissa Kaloga4, Siaka Soumaoro1, \\ Doumbia Kadidiatou Singare ${ }^{1}$, Samba Karim Timbo', Mohamed Amadou Keita1
}

${ }^{1}$ ENT and Head and Neck Surgery Department, Gabriel Toure University Hospital, Bamako, Mali

${ }^{2}$ ENT and Head and Neck Surgery Department, Mother-Child "Luxembourg" Hospital, Bamako, Mali

${ }^{3}$ ENT and Head and Neck Surgery Department, Reference Health Kalanbancoro, Bamako, Mali

${ }^{4}$ Anesthesia Resuscitation Department, Mother-Child "Luxembourg” Hospital, Bamako, Mali

Email: diarrakassim84@yahoo.fr

How to cite this paper: Diarra, K., Konaté, N., Sidibé, Y., Sissoko, T., Koné, F.I., Guindo, B., Sanogo, H., Kaloga, B.D., Soumaoro, S., Singare, D.K., Timbo, S.K. and Keita, M.A. (2019) Surgery of the Goiter in the ENT Department of Chu Gabriel Toure: Problematic and Perspective. International Journal of Otolaryngology and Head \& Neck Surgery, 8, 283-291.

https://doi.org/10.4236/ijohns.2019.86026

Received: August 17, 2019

Accepted: November 24, 2019

Published: November 27, 2019

Copyright ( 2019 by author(s) and Scientific Research Publishing Inc. This work is licensed under the Creative Commons Attribution International License (CC BY 4.0).

http://creativecommons.org/licenses/by/4.0/

(c) (i) Open Access

\begin{abstract}
Aims: To describe the diagnostic aspects, surgical indications and post-operative complications of thyroidectomies performed in our department. Materials and method: A descriptive retrospective study that took place in the ENT Department and Cervicofacial Surgery of Gabriel TOURE University Hospital of Bamako. We did a comprehensive sampling of all goiter cases from January 2013 to December 2018. Were included in the study, the records of patients of all ages and genders, admitted into the ward and scheduled for thyroidectomy (partial or total). The exclusion criteria were incomplete hospitalization records. There were a total of 139 files were retained. Results: In 60 months, 139 cases were collected out of 1720 patients hospitalized for surgery, representing a hospital prevalence of $8.08 \%$. The average age was 46.89 years. (123 women and $16 \mathrm{men}$ ). The socio-professional categories were dominated by housewives (68.34\%). The reported functional signs were tachycardia, asthenia and other signs of dysthyroidism in $59 \%$ as well as signs of compression in $24.46 \%$. In 72 cases or $51.80 \%$, the patients consulted between 2 and 10 years of disease progression. Twenty patients or $14.39 \%$ had a history of familial goiter and 2 patients had a history of thyroid surgery. On physical examination the swelling was antero-cervical in 56.83\% of cases. In 96 cases or $69.06 \%$ the glandular diameter was between 5 and $9 \mathrm{~cm}$. In 2 cases or $1.43 \%$ we noted cervical adenopathy in the jugulo-carotid chain. Ultrasound, TSHus and fT4 were performed first-line and systematically in all our patients. Ultrasound objectified an appearance of multinodular goiter in 106 cases or $76.26 \%$. In $60.43 \%$ of cases the patients were TI classes RADS 3, they
\end{abstract}


were TI RADS $4 \mathrm{~A}$ in 16 cases or $11.51 \%$. CT scans were performed in 3 patients or $2.15 \%$ to specify the loco-regional extension, to look for possible lymph node invasion, and to compress or dipping the goiter. Surgical indication was placed in front of a multinodular goiter (GMN) in 106 cases or $76.26 \%$, a single goiter in 11 cases or $7.9 \%$, a single nodule greater than $3 \mathrm{~cm}$ in 17 cases or $12.23 \%$, Basedow disease in 4 cases or $2.88 \%$ and a recurrence in one case $0.72 \%$. We performed a lobo-isthmectomy in $56.11 \%$, a total thyroidectomy in $20.14 \%$ of cases, subtotal in $20.86 \%$ of cases and total thyroidectomy with mediation-recurrent lymph node curage and bilateral jugulocarotidien in 4 cases or $2.87 \%$. Recurrent nerves were systematically searched and seen in all cases. Replacement therapy was indicated in all patients who underwent a total thyroidectomy. Complications recovered were 1 case of compressive hematoma, 6 cases of transient dysphonies and cough, 4 cases of definitive hypocalcemia. 1 case of recurrence, but no deaths were observed. Histopathology performed in all of our patients was dominated by vesicular and colloid adenoma. Conclusion: Thyroid surgery is a common surgery but not devoid of complications, the most dangerous of which remain recurrent impairment and definitive hypoparathyroidism. The experience of all surgical teams in the vasculo-nervous anatomy of the neck is the best guarantor to reduce and prevent complications.

\section{Keywords}

Goiter, Thyroidectomy, Recurrent Surgery

\section{Introduction}

A goiter is a localized or generalized enlarged thyroid body. It is usually cervical but may have intrathoracic development by exceeding the upper opening of the chest [1]. On the radiological level goiter is when the thyroid volume measured in ultrasound is $18 \mathrm{ml}$ in women, $20 \mathrm{ml}$ in men [2]. Thyroid surgery has a special place in the treatment of multiple thyroid pathologies [3]. Its practical realization requires a perfect mastery of the anatomy of the cervical region. It consists of the partial or total removal of the thyroid gland. There are several varieties ranging from lobectomy to lobo-isthmectomy, isthmectomy and total thyroidectomy [4]. The haunting of the cervical surgeon is the management of cancer pathologies and the prevention of complications related to this surgery. Currently this morbidity is reduced thanks to better medical and endocrine preparation of patients as well as the use of monitoring and video surgery in the research and preservation of vasculo-nervous pedicules and glands parathyroids [4]. The purpose of our study was to evaluate the experience of the service in the surgical management of goiters and to compare the results of our study with those of the literature.

\section{Materials and Method}

This was a retrospective, descriptive study carried out in the ENT and Cervi- 
co-facial Surgery Department of the Gabriel TOURE University Hospital in Bamako. We did a comprehensive sampling of all goiter cases from January 2013 to December 2018. Included in the study were the records of patients of all ages and genders, admitted into the ward and scheduled for thyroidectomy (partial or total). The non-inclusion criteria were incomplete hospitalization records. There were 19 of them. A total of 139 files were retained.

\section{Variables Studied}

- Socio-demographic aspects (age, gender, occupation, residence);

- Clinical aspects: goiter size, palpatory data;

- Paraclinical aspects: TIRADS classification;

- Therapeutic aspects: technique and postoperative follow-up ranging from 6 to 1 year.

\section{Results}

\subsection{Hospital Frequency}

In 60 months, 139 cases were collected out of 1720 patients hospitalized for surgery, representing a hospital prevalence of $8.08 \%$.

\subsection{Socio-Demographic Aspects}

The female sex represented 123 cases or a sex ratio of 0.13 . The average age was 46.89 years with extremes of 16 and 74 years (Figure 1). The socio-professional categories were in declining order women in the home (68.34\%), Traders (10.80\%), Workers (9.35\%), Middle Managers (5.75\%), Pupils/Students (3.60), Senior Executives (2.15\%).

\subsection{Clinical Aspects}

The reported functional signs were tachycardia, asthenia and other signs of dysthyroidism in $59 \%$ as well as signs of compression in $24.46 \%$. In 72 cases or $51.80 \%$ the patients consulted between 2 and 10 years of disease progression. Twenty patients or $14.39 \%$ had a history of familial goiter and 2 patients had a history of thyroid surgery. On physical examination the swelling was antero-cervical in $56.83 \%$ of cases. In 96 cases or $69.06 \%$ the glandular diameter was

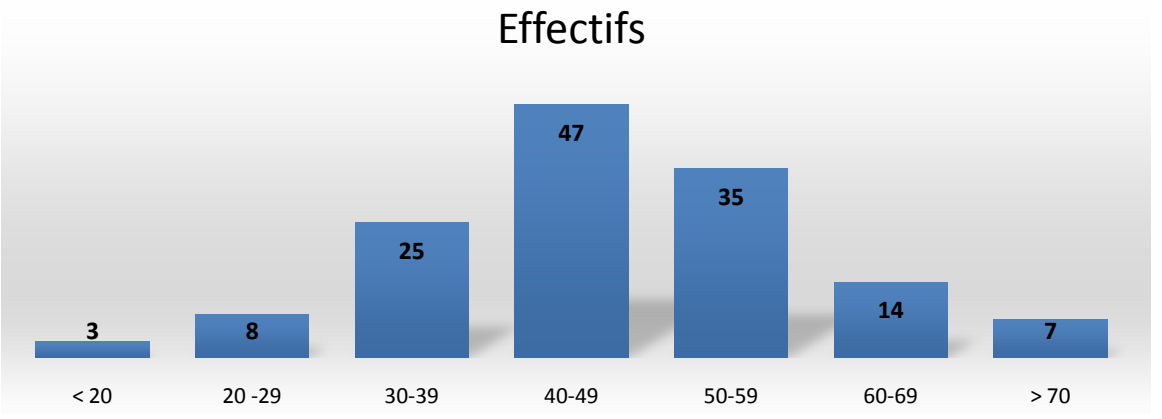

Figure 1. Distribution of patients by age group. 
between 5 and $9 \mathrm{~cm}$. In 2 cases or $1.43 \%$ we found cervical adenopathy in the jugulo-carotid chain.

\subsection{Paraclinical Aspects}

Ultrasound, TSHus and fT4 were performed first-line and systematically in all of our patients. Ultrasound objectified an appearance of multinodular goiter in 106 cases or $76.26 \%$. In $60.43 \%$ of cases the patients were RADS 3 TI classes, they were TI RADS $4 \mathrm{~A}$ in 16 cases or $11.51 \%$ and in 2 cases or $1.43 \%$ they were RADS $4 \mathrm{~B}$ TI classes. CT scans were performed in 3 patients, or $2.15 \%$ to specify the loco-regional extension, to look for possible lymph node invasion, and to compress or dipping the goiter. The hormonal check-up carried out systematically in all our patients found euthyroidism in 43 cases or $30.9 \%$, hyperthyroidism in 96 cases or $69.06 \%$, zero cases of hypothyroidism. Hormonal treatment after advice from the endocrinology department has been initiated in all patients with hyperthyroidism.

\subsection{Therapeutic Appearance}

Surgical indication was placed in front of a multi nodular goiter (GMN) in 106 cases or $76.26 \%$, a single goiter in 11 cases or $7.9 \%$, a single nodule greater than 3 $\mathrm{cm}$ in 17 cases or $12.23 \%$, Basedow disease in 4 cases or $2.88 \%$ and a recurrence in one case is $0.72 \%$ (Table 1 ). We performed a lobo-isthmectomy in $56.11 \%$, a total thyroidectomy in $20.14 \%$ of cases, a subtotal thyroidectomy in $20.86 \%$ of cases and total thyroidectomy with mediatino-recurrent lymphnode cure and jugulo-carotidien bilaterally in 4 cases or $2.87 \%$ (Table 2). Recurrent nerves were systematically searched and seen in all cases. Replacement therapy was indicated in all patients who underwent a total thyroidectomy. Complications recovered were 1 case of compressive hematoma, 6 cases of transient dysphonies and cough, 4 cases of definitive hypocalcemia. 1 case of recurrence, but no deaths were observed (Table 3 ).

\subsection{Histological Aspect}

For all the files studied, the anatomopathology results concluded cancer in 3 cases: $2.16 \%$ (2 cases of vesicular carcinomas and 1 case of undifferentiated carcinoma), Ridel's thyroiditis in one case and the rest was dominated by vesicular and colloid adenoma (Table 4).

Table 1. Distribution of patients according to the indication for surgery.

\begin{tabular}{ccc}
\hline Indication & Effective & Percentage \% \\
\hline Simple goiter & 11 & 7.91 \\
Multinodular goiter & 106 & 76.26 \\
Single nodule $>3 \mathrm{~cm}$ & 17 & 12.23 \\
Basedow disease & 4 & 2.88 \\
Recidivism & 1 & 0.72 \\
Total & 139 & 100
\end{tabular}


Table 2. Distribution of patients according to the operative technique.

\begin{tabular}{ccc}
\hline Chirurgical method & Effective & Percentage \% \\
\hline Lobo-isthmectomy & $\mathbf{7 8}$ & 56.11 \\
Subtotal thyroidectomy & 29 & 20.86 \\
Total thyroidectomy without cleaning & 28 & 20.14 \\
Total thyroidectomy with cleaning & 4 & 2.87 \\
Total & 139 & 100 \\
\hline
\end{tabular}

Table 3. Distribution of patients according to postoperative incidents.

\begin{tabular}{ccc}
\hline Complication and postoperative evolution & Effective & Percentage \% \\
\hline Compressif hematoma & 1 & 0.72 \\
Hypocalcemia & 4 & 2.87 \\
Nothing & 127 & 91.37 \\
Dysphonia and transient cough & 6 & 4.32 \\
Récidivism & 1 & 0.72 \\
Total & 139 & 100 \\
\hline
\end{tabular}

Table 4. Distribution of patients according to pathological findings.

\begin{tabular}{ccc}
\hline Different histological type & Effective & Percentage \% \\
\hline Thyroiditis of Ridel & 1 & 0.72 \\
Vesicular adenoma & 37 & 26.62 \\
Colloid adenoma & 53 & 38.13 \\
Vesiculo-colloid adenoma & 31 & 22.30 \\
Cyst & 14 & 10.07 \\
Vesicular carcinoma & 2 & 1.44 \\
Undifferentiated carcinoma & 1 & 0.72 \\
Total & 139 & 100 \\
\hline
\end{tabular}

\section{Discussion}

\subsection{Methodological Aspects}

We conducted a retrospective and descriptive study on the surgical management of goiters in the ENT Department of the Gabriel TOURE University Hospital. It lasted for 5 years (January 2013 to December 2018). Retrospectiveness has given a number of limitations to our study.

- Poor preservation of archives;

- Lack of reliable and usable data in some files during the retrospective phase;

- The change of address of patients or contact persons in Bamako Failure to meet appointments for post-operative control by some patients;

- The medium- and long-term post-operative follow-up survey was conducted using hospital record often supplemented by home visits. The phone was used 
to reach patients who are outside Bamako.

\subsection{Hospital Frequency Aspect}

In 5 years we performed 139 thyroidectomies, or $8.08 \%$ of all surgeries in the ward (n-1720). African studies on the subject have found frequencies significantly higher than our series [5] [6]. This weakness in our hospital frequency could be explained by the fact that this surgery is also practiced in the various departments of visceral surgery.

\subsection{Socio-Demographic Aspects}

The average age of our patients was 46.89 years, which is no different statistically from that of African authors such as Ouedrago [7] in Burkina Faso, Dia DG [8] in Senegal, who were 46 years old, and 40 years respectively. In general the average age in thyroid pathology varies between 40 and 60 years [7] [9], so it is the prerogative of the young adult subject. In our study we noted a female predominance in $\mathbf{8 8 . 4 \%}$. This same observation has been corroborated by the literature [3] [7] [9]. Female predominance appears to show only that from puberty, which is explained by the intervention of hormonal factors, the presence of estrogen receptors on the vesicular cells whose growth they promote. In addition, estrogens reduce the activity of the iodine symporter and contribute to the depletion of thyroid iodine content. Pregnancy promotes the onset or development of goiters, due to hyperestrogenengineering, thyreostimulant activity of placental HCG, supply of iodine and hormones to the fetus, and finally to increased renal clearance of iodine [10].

\subsection{Clinical Aspects}

The consultation period varies from different studies to less than 10 years. In our series more than half of the patients had a disease progression period between 2 - 10 years. This is similar to that of some authors [5] [7]. Goiter remains asymptomatic for a long time, which does not motivate consultation very early. There are also social beliefs that patients only consult when swelling becomes very troublesome by its volume or when signs of complications and compression appear or in the face of signs of dysthyroidism. The most common reason for consultation is low anterior cervical swelling. Sometimes signs of compression or signs of dysthyroidism can be noted [7] [11]. In our study the reported functional signs were tachycardia, asthenia and other signs of dysthyroidism in 59\% as well as signs of compression in $24.46 \%$.

\subsection{Paraclinical Aspects}

Ultrasound was routinely performed in all of our patients. This is the reference test for thyroid nodule analysis, and for the detection of subclinical nodules (1 $3 \mathrm{~mm}$ ). Ultrasound criteria for suspicion of malignancy have been established. Recent studies have shown that several criteria taken in isolation have no formal 
value; in contrast, the association of several traits with a proven predictive value with the diagnosis of cancer [11]. In our study, data from cervical ultrasound reports identified 2 suspicious nodules CLASSEs TI-RADS $4 \mathrm{~b}$ whose histology concluded to carcinomas. CT scans allow a detailed morphological study of the intrathoracic portion of the goiter that is inaccessible to ultrasound. It will specify the lower and posterior limits of the goiter, its relationship with large thoracic cervico vessels and with the oeso-tracheal axis [9] [12]. In our study it was carried out in 5 suspected cases of plunging goiter and confirmed the delipping character in the mediatin associated with deviation of the tracheal axis.

\subsection{Therapeutic Aspect}

Surgical techniques are related to surgical indications. So our surgical indications were multi nodular goiters with or without compression, Basedow disease, single goiters and single nodules greater than $3 \mathrm{~cm}$ for which we practiced either a total thyroidectomy or an isthmolobectomy. These same indications have been reported by the authors [4] [5]. Today the majority of authors prefer total thyroidectomy for the surgical treatment of toxic multi nodular goiters with hormone therapy [5] [13].

\subsection{Surgical Suites}

In the surgical suites, the incidence of postoperative bleeding ranges from $0 \%$ to $6.5 \%$. Male sex, the presence of cancer, the importance of the gesture, and the surgeon's experience seem to be favourable factors [7] [14]. Prevention involves preoperative control of possible dysthyroidism, intraoperative hemostasis control, and Valsalva manoeuvre to be performed in accordance with the anaesthetist, and postoperatively by early resumption of antihypertensive treatments. In our series we noted it in one case $(0.7 \%)$ requiring an opening of the thyroid lodge with drainage of the hematoma and hemostasis of the vessel responsible. The incidence of recurrent, unial or bilateral impairment during a thyroidectomy is low but not zero. The risk of recurrent paralysis is present regardless of thyroid gesture. These include the type of surgery [9], the underlying thyropathy, the extent of the exeresis, and the volume of activity of the surgeon. The risk is increased by the presence of cancer that imposes central curage or invades adjacent structures. Other factors were mentioned: cervical hyperextension, which stretches the nerve, the number of branches dividing the recurrent, the size of the recurrent. The prevention of recurrent paralysis is both pre- and intraoperative. Neuromonitoring (NIM) used in thyroid surgery for ten years by some teams, has been developed as an aid to the intraoperative identification of the nerve, and to the elucidation of the mechanisms involved in recurrent paralysis [9] [15]. We do not have NIM in our technical tray, but the objective is the effective acquisition in a short time to further minimize the risk of recurrent injury. In our study, recurrent lesions were $2.8 \%$ transient and transient. In the literature the rate of recurrent injury varies between $0.5 \%$ and 3.5\% [14] [15].

The risk of postoperative hypocalcemia, transient or permanent, is increased 
by several factors: venous drainage of parathyroids, which is done exclusively to the thyroid for the upper parathyroids; the situation under capsular frequents in cases of large goiter or more rarely the intrathyroid situation of parathyroids, most often lower, not detectable in operative. The rate of involuntary parathyroidectomy varies from $6 \%$ to $21 \%$ depending on the authors, causing transient hypocalcemia in $50 \%$ of cases, with a risk of definitive hypocalcemia in about $2 \%$ [16] [17] [18]. In our study 4 cases (2.87\%) transient hypocalcemias have been observed and treated with calcium associated with vitamin D.

\subsection{Anatomopathological Aspect}

Histopathology can find all aspects of transition between simple hyperplasia, adenoma, differentiated cancer and anaplastic cancer. For all the files studied, we found to the results that it was a benign pathology in $97.84 \%$ and 3 cases of malignant tumors or $2.16 \%$. Its results are comparable to those of some authors [5] [8].

\section{Conclusion}

Thyroid pathology has been the subject of numerous studies, but it still poses a public health problem due to the large number of outbreaks of goitreuse endemics. Thyroid surgery is a common surgery but not devoid of complications, the most dangerous of which remain recurrent impairment and definitive hypoparathyroidism. The experience of all surgical teams in the vasculo-nerve anatomy of the neck is the best guarantor to reduce and prevent complications.

\section{Conflicts of Interest}

The authors declare no conflicts of interest regarding the publication of this paper.

\section{References}

[1] Benbakh, M., Abou-elfadl, M., Rouadi, S., Abada, R.-L., Roubal, M. and Mahtar, M. (2016) Goitres plongeants: Expérience du service à propos de 50 cas. Annales françaises d oto-rhino-laryngologie et de pathologie cervico-faciale, 133, 17-20. https://doi.org/10.1016/j.aforl.2015.01.011

[2] Sidibé, Y., Haidara, A.W., et al. (2019) Surgical Management of Larges Goiters in the ENT Department of CHU Mother and Child "Luxembourg". International Journal of Otolaryngology and Head \& Neck Surgery, 8, 139-149. https://doi.org/10.4236/ijohns.2019.84016

[3] Illé, S., James Didier, L., Saidou, A., Timi, N. and Sani, R. (2017) Résultats De 5 ans De Thyroïdectomie Au Service D’orl Et Chirurgie Cervico-Faciale De l'Hôpital National De Niamey (Niger). European Scientific Journal, 13, 44-52. https://doi.org/10.19044/esj.2017.v13n21p44

[4] N'gouan, J.M., Téa, Z.B., et al. (2011) La chirurgie thyroidienne en ORL à Abidjan. Rev. Col. Odonto-Stomatol. Revue de Stomatologie, de Chirurgie Maxillo-faciale et de Chirurgie Orale, 18, 45-49.

[5] Leyes, A., et al. (2016) Les thyroïdectomies au centre hospitalier national de Pi- 
kine-Dakar (CHNP): Indications et résultats chez 417 patients. Revue Africaine de Médecine Interne, 3, 36-40.

[6] Poumale, F., Doui, A.D., et al. (2017) La Chirurgie Thyrö̈dienne à Bangui: Indications et Suites Opératoires à Propos de 135 Cas. Human Health and Disease, 18, $39-43$.

[7] Ouédraogo, B.P., et al. (2016) Les goitres en ORL: Aspects épidémiologiques, diagnostiques et thérapeutiques. La revue africaine $d$ ORL et de chirurgie cervico-faciale, 16, 1-5.

[8] Dia, D.G. and Tall, H. (2016) Profil épidémiologique, clinique et étiologique des goitres à Saint Louis Sénégal. Revue Africaine de Médecine Interne, 3, 41-46.

[9] Tabchouri, N., Anil, Z., et al. (2018) Morbidité de la thyroïdectomie totale pour goitre plongeant: série de 70 patients. Journal de Chirurgie Viscérale, 155, 10-15. https://doi.org/10.1016/j.jchirv.2017.01.008

[10] Wémeau, J.L. (2011) Prise en charge thérapeutique des goitres. La Presse Médicale, 40, 1147-1154. https://doi.org/10.1016/j.lpm.2011.10.005

[11] Benamar, A.I.T., et al. (2017) Morbidity of Total Thyroidectomy for Substernal Goiter: A Series of 70 Patients. Journal of Visceral Surgery, 10, 5-6.

[12] Brenet, E., Dubernard, X., et al. (2017) Évaluation et la prise en charge des goitres cervico-médiastinaux. Annales françaises d oto-rhino-laryngologie et de pathologie cervico-faciale,134, 391-395. https://doi.org/10.1016/j.aforl.2017.04.002

[13] Youssef, D., Mohamed, A.H., et al. (2018) Chirurgie des hyperthyroïdies: À propos de 60 cas. Pan African Medical Journal, 31, 1-8.

[14] Vincent, G. (2008) Thyroidectomy over a Quarter of a Century in the Belgian Ardennes: A Retrospective Study of 1207 Patients. Acta Chirurgica Belgica, 108, 542-547. https://doi.org/10.1080/00015458.2008.11680282

[15] Périé, S., Aït-Mansour, A., et al. (2013) Intérêt du monitorage du nerf laryngé inférieur dans la stratégie opératoire au cours des thyroïdectomies et parathyroïdectomies totales. Annales françaises d'oto-rhino-laryngologie et de pathologie cervicofaciale, 130, 134-139. https://doi.org/10.1016/j.aforl.2013.01.004

[16] Khairy, G.A. and Al-Saif, A. (2011) Incidental Parathyroidectomy during Thyroid Resection: Incidence, Risk Factors, and Outcome. Annals of Saudi Medicine, 31, 274-278. https://doi.org/10.4103/0256-4947.81545

[17] Biet, A., Zaatar, R., Strunski, V. and Page, C. (2009) Complications postopératoires dans la thyroidectomie totale pour maladie de Basedow: Comparaison avec la chirurgie des goitres non basedowiens. Annales d oto laryngologie et chirurgie cervicofaciale, 126, 190-195. https://doi.org/10.1016/j.aorl.2009.06.003

[18] Christou, N. and Mathonnet, M. (2013) Quelles sont les complications après thyroïdéctomie totale. Journal de Chirurgie Viscérale, 150, 276-284. https://doi.org/10.1016/j.jchirv.2013.03.004 